\title{
Intra-familial phenotypic heterogeneity in a Sudanese family with DARS2-related leukoencephalopathy, brainstem and spinal cord involvement and lactate elevation: a case report
}

\author{
Ashraf Yahia 1,9,12, Liena Elsayed ${ }^{1 *}$ (D), Arwa Babai ${ }^{2}$, Mustafa A. Salih³ ${ }^{3}$ Sarah Misbah El-Sadig ${ }^{4,8}$, Mutaz Amin ${ }^{1}$, \\ Mahmoud Koko ${ }^{5}$, Rayan Abubakr ${ }^{2}$, Razaz Idris², Shaimaa Omer M.A. Taha ${ }^{6}$, Salah A. Elmalik ${ }^{13}$, Alexis Brice ${ }^{11,12}$, \\ Ammar Eltahir Ahmed ${ }^{7,8}$ and Giovanni Stevanin ${ }^{10,12}$
}

\begin{abstract}
Background: Leukoencephalopathy with brainstem and spinal cord involvement and lactate elevation (LBSL, OMIM \#611105) is a genetic disease of the central nervous system characterized by lower limb spasticity, cerebellar ataxia and involvement of the dorsal column. The disease is caused by mutations in the DARS2 gene but has never been reported in sub-Saharan Africa so far.

Case presentation: Two siblings, aged 18 years and 15 years, from a consanguineous family presented with pyramidal signs and symptoms since infancy and developmental delay. Whole exome sequencing of the proband identified two compound heterozygous variants (NM_018122.4:c.1762C > G and c.563G > A) in DARS2. Sanger sequencing confirmed the presence of the mutations and their segregation in trans in both patients and in their elder sister (aged 20 years), who showed only brisk reflexes and mild lower limb spasticity. Surprisingly, in contrast to her subtle clinical presentation, the elder sister had abnormal MRI features and serum lactate levels comparable to her ill sisters.

Conclusion: This report illustrates intra-familial phenotypic variation in LBSL and provides an example of a marked dissociation between the clinical and radiological phenotypes of the disease. This may have implications for the detection of mutation carriers in LBSL.
\end{abstract}

Keywords: LBSL, DARS2, Clinico-radiological dissociation, Intra-familial phenotypic heterogeneity, Africa

\section{Background}

Leukoencephalopathy with brainstem and spinal cord involvement and lactate elevation (LBSL, OMIM \# 611105) is a genetic disease of the central nervous system characterized by lower limb spasticity, cerebellar ataxia and involvement of the dorsal column [1]. The clinical presentation is variable both in age at onset (early childhood or adulthood) and in associated features (learning difficulty, epilepsy, mental deterioration and others) [2]. Brain

\footnotetext{
* Correspondence: doctorlbo@hotmail.com

${ }^{1}$ Department of Biochemistry, Faculty of Medicine, University of Khartoum, Khartoum, Sudan

Full list of author information is available at the end of the article
}

magnetic resonance imaging (MRI) shows diffuse cerebral white matter changes with signal abnormalities in the dorsal column and lateral corticospinal tracts in addition to spectroscopic findings of increased lactate [1].

LBSL is an autosomal recessive disease caused by mutations in DARS2 [3]. This gene, located on chromosome 1, has 17 exons and encodes the mitochondrial aspartyl-tRNA synthetase [3]. Defects in this gene in neurons impair the translation of mitochondrial mRNAs, leading to mitochondrial dysfunction and progressive cell loss [4]. We report here the identification of two compound heterozygous rare variants (NM_018122.4:c.1762C > G and c.563G > A) segregating in a Sudanese family with a wide clinical spectrum of 
LBSL and a marked dissociation between clinical and radiological phenotypes in one of the affected siblings.

\section{Case presentation}

Two siblings, aged 18 years and 15 years, from a Sudanese family (individuals 2043 and 2044) presented with pyramidal features since infancy (Table 1). Both patients were the outcome of uncomplicated normal vaginal deliveries and developed normally before the initial symptoms of the disease. Patient 2043 developed her symptoms from the age of 8 months after an attack of fever complicated by febrile convulsions. Initially, she manifested floppiness, which later turned into spasticity. Speech and walking were delayed (achieved at ages 3-4 and 6 years, respectively). At the age of 10 months she had three attacks of seizures, which were later controlled by carbamazepine. Spasticity progressed over time and currently the patient can only walk with support. In patient 2044, the disease started at the age of 4 months with initial floppiness followed by spasticity and delayed motor development as well, but without any history of convulsions or precipitating febrile illness. Speech developed normally. Her motor disability was analogous to that of her sister. Examination of the lower limbs showed severe spasticity, hyperreflexia and "up-going" plantar reflex in both patients. Whereas patient 2043 showed severe proximal and distal lower limb weakness, patient 2044 manifested only moderate proximal weakness. Due to the severe spasticity, heel on shin test was not applicable. Upon examination of the upper limbs, the two patients showed increased reflexes with normal tone and a normal finger-to-nose test. Ocular cerebellar signs (nystagmus, slow saccades and interrupted pursuit) were present in both patients. There were no extrapyramidal signs.

Table 1 Clinical characteristics of the described genetically affected siblings

\begin{tabular}{|c|c|c|c|}
\hline Patient ID & 2042 & 2043 & 2044 \\
\hline Gender & Female & Female & Female \\
\hline Age at examination & 20 years & 18 years & 15 years \\
\hline Age at onset & - & 8 months & 4 months \\
\hline Initial sign / symptom & $\begin{array}{l}\text { Hypertonia and hyperreflexia } \\
\text { detected during the sampling } \\
\text { session }\end{array}$ & Floppiness & Floppiness \\
\hline Delayed motor development & - & + & + \\
\hline Delayed speech & - & + & - \\
\hline Epilepsy & - & + & - \\
\hline Cognitive impairment & - & - & - \\
\hline Degree of motor disability & $\begin{array}{l}\text { No functional handicap but } \\
\text { signs at examination }\end{array}$ & $\begin{array}{l}\text { Walk with } \\
\text { support / unable to run }\end{array}$ & $\begin{array}{l}\text { Walk with support / unable } \\
\text { to run }\end{array}$ \\
\hline Muscle wasting (UL \& LL) & - & - & - \\
\hline UL hypertonia & - & - & - \\
\hline UL motor deficit & - & - & - \\
\hline UL hyperreflexia & + & + & + \\
\hline LL hypertonia & + & + & + \\
\hline LL motor deficit & - & Severe & Moderate \\
\hline LL hyperreflexia & + & + & + \\
\hline Sensory impairment & - & - & - \\
\hline Dysarthria & - & + & + \\
\hline Ocular cerebellar signs & - & + & + \\
\hline Dysmetria & - & - & - \\
\hline Optic atrophy & - & - & - \\
\hline Clinical summary & Pyramidal features & $\begin{array}{l}\text { Pyramidal features, seizures, delayed } \\
\text { speech, ocular cerebellar signs and } \\
\text { dysarthria }\end{array}$ & $\begin{array}{l}\text { Pyramidal features, ocular } \\
\text { cerebellar signs and dysarthria }\end{array}$ \\
\hline $\begin{array}{l}\text { MRI changes in brain and } \\
\text { spinal cord }\end{array}$ & + & + & + \\
\hline $\begin{array}{l}\text { Serum lactate level in } \mathrm{mmol} / \mathrm{L} \\
\text { (reference range } 0.5-2.2 \mathrm{mmol} / \mathrm{L} \text { ) }\end{array}$ & 6.13 & 6.8 & 5.97 \\
\hline
\end{tabular}

UL upper limb, LL lower limb, - absent, + present 
Sensory nervous system and fundus examinations were normal. Both patients had normal cognitive functions and they were able to graduate from high school and attend university. Brain MRIs of patients 2043 and 2044 showed abnormal high signal intensity in the periventricular white matter and dentate nuclei bilaterally together with thinning of corpus callosum and cerebral and cerebellar atrophy (Fig. 1).
Spinal MRI showed signal changes with dorsal spinal cord atrophic changes in both these affected sisters.

Four first-degree relatives were assessed for inclusion as controls in the genetic analysis: the parents (2040 and 2041), an elder sister (2042), and a younger sister (2045). They underwent routine clinical examination to rule out the possibility of subtle abnormalities. The examination was normal in the parents and the younger sister. The

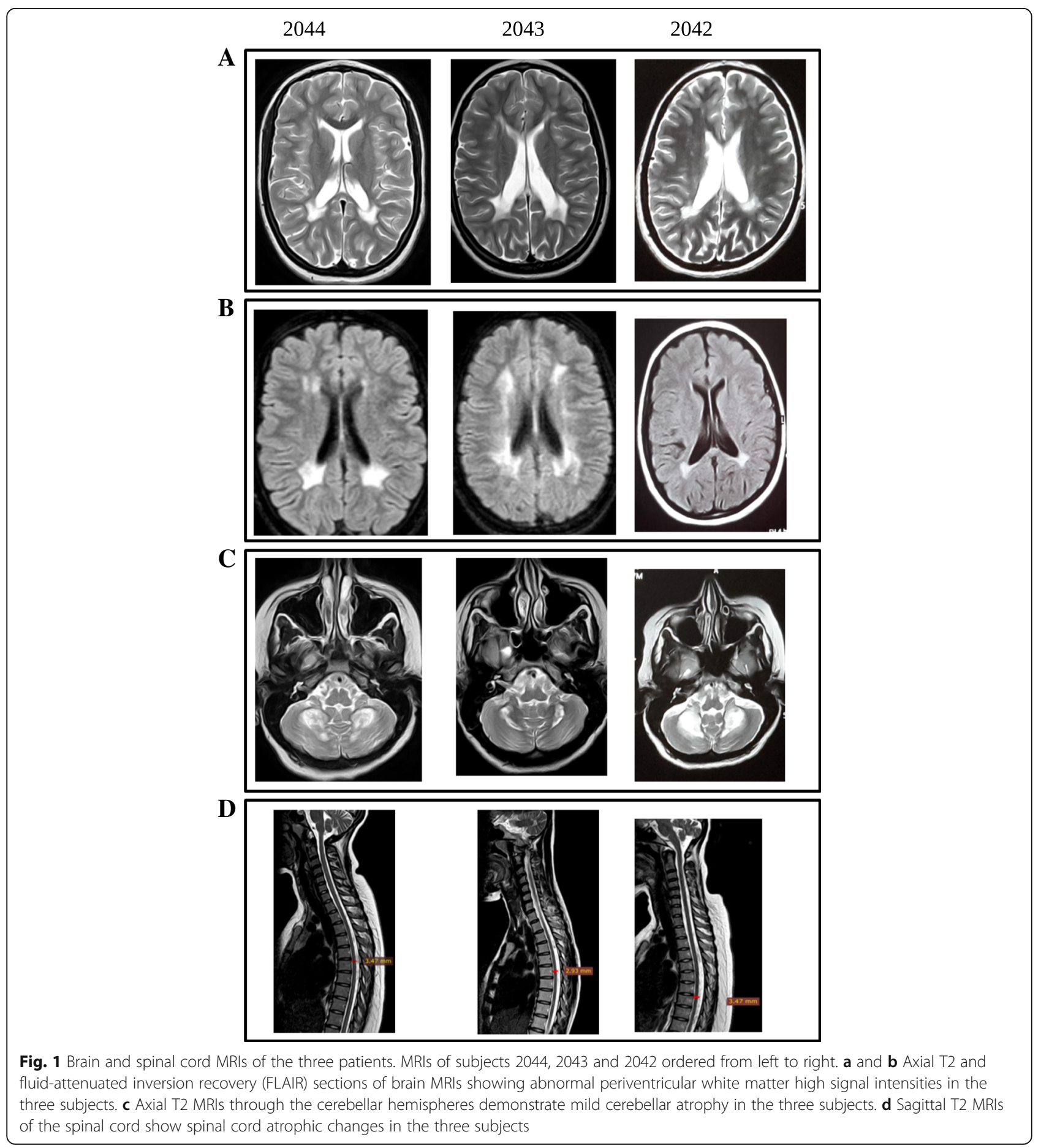


elder sister showed brisk reflexes in both upper and lower limbs and mild spasticity in the lower limbs but no other clinically detectable abnormality (Table 1 ).

DNA was extracted from saliva samples. Whole exome sequencing was performed in the proband (patient 2043) and revealed two compound heterozygous rare variants in the DARS2 gene (NM_018122.4: c.1762C > G and NM_018122.4: c.563G > A; p.(Leu588Val) and p.(Arg188 Gln), respectively). The variants were predicted as pathogenic using three pathogenicity prediction tools (SIFT [5], PolyPhen-2 [6] and MutationTaster [7]). The variant c.1762C $>\mathrm{G}$ (rs972404343) was reported as "likely pathogenic" in the ClinVar database [8]; it was absent from both the ExAC and gnomAD databases [9]. The second variant, c.563G > A (rs182811621), was not reported in the ClinVar database but had very low allele frequencies in the ExAC and gnomAD databases (0.00001 and 0.000004, respectively) [9]. Sanger sequencing (Fig. 2) identified the father and mother as heterozygous carriers of the single variant c. $1762 \mathrm{C}>\mathrm{G}$ and c.563G > A, respectively, and validated the presence of both variants in patients 2043 and 2044. Additionally, subject 2042, who had only mild signs on examination, was found to harbor both variants.

To further investigate the genotype-phenotype correlation as well as the association between the clinical and radiological findings, brain and spinal MRIs were obtained for patient 2042. Interestingly, she presented similar features to her affected siblings in the form of periventricular white matter, dentate nuclei, medulla

A
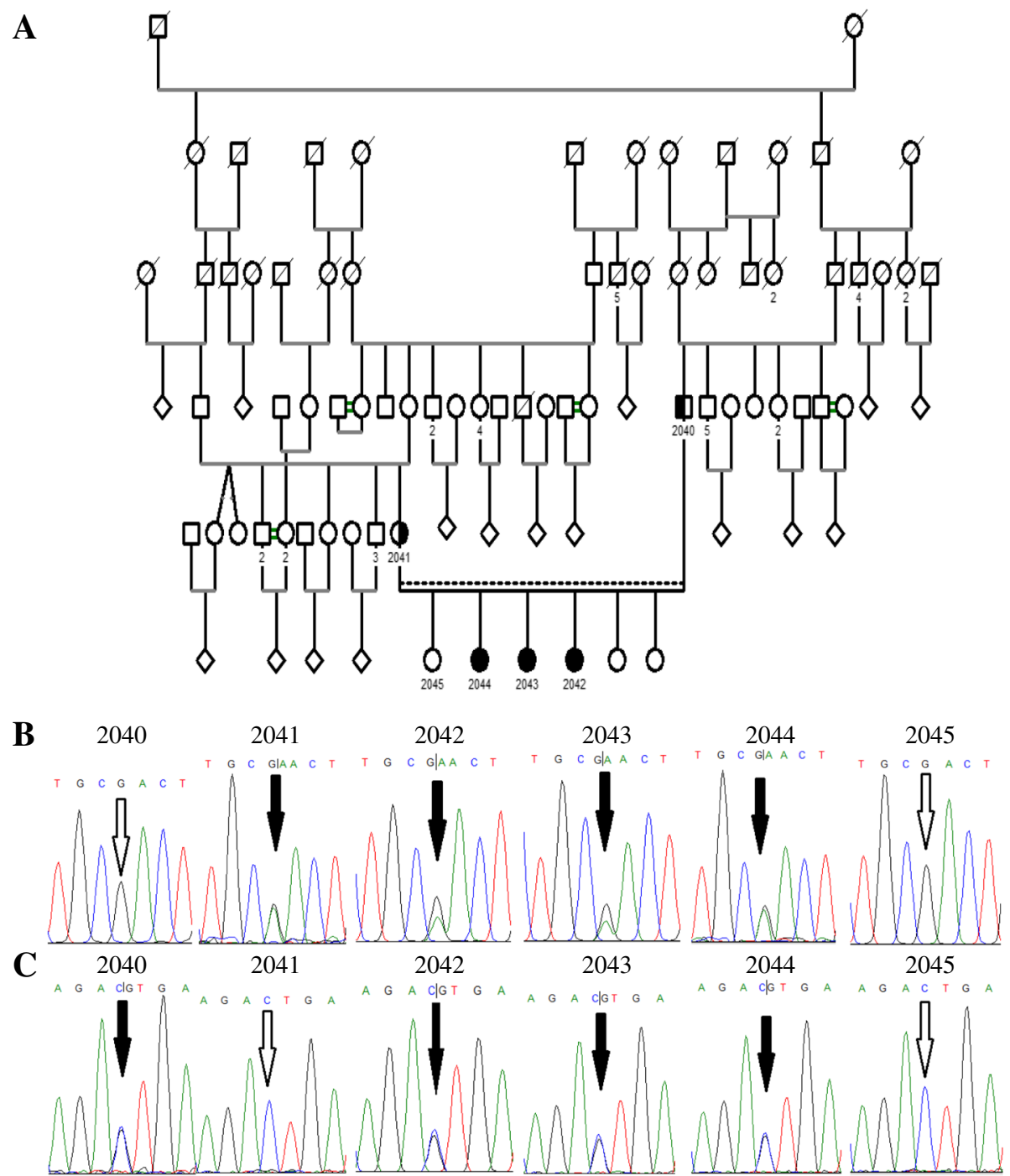

Fig. 2 Pedigree and segregation analysis. Segregation analysis shows compound heterozygous pattern of disease inheritance. a Family pedigree. b and c Electropherograms showing the segregation pattern of c.563G > A and c.1762C > G (black arrows), in (b) and (c), respectively; in subjects 2040, 2041 (parents), 2045 (healthy sister), 2042, 2043 and 2044 (patients). White arrows point to wild type variants at the genomic positions of interest. The variant c.563G > A is inherited from the mother (2041) while the variant c.1762C > G is inherited from the father 
oblongata and cervical spinal cord areas of signal changes and cerebral and spinal cord atrophic changes (Fig. 1). Biochemical investigations showed an elevated serum lactate level (reference range: $0.5-2.2 \mathrm{mmol} / \mathrm{L}$ ) in patients 2043 and $2044(6.8 \mathrm{mmol} / \mathrm{L}$ and $5.97 \mathrm{mmol} / \mathrm{L}$, respectively) and in patient $2042(6.13 \mathrm{mmol} / \mathrm{L})$ as well. Currently, the younger patients are on regular physiotherapy. No further medical intervention has been undertaken in the minimally affected elder sister.

\section{Discussion and conclusion}

Compound heterozygous mutations are implicated in the majority of LBSL cases [10]. There is a wide variety in the clinical presentation of patients [10]. In addition, there is no apparent genotype-phenotype correlation nor is there a correlation between the degree of mitochondrial aspartyl-tRNA synthetase dysfunction and disease severity [11]. In this report, we showed that patients in the same family with the same compound heterozygous mutations can vary in their clinical presentations from an apparently healthy individual (with findings limited to brisk reflexes incidentally recognized at age 20 years) to disabled patients. Additionally, we highlighted the marked dissociation that can occur between clinical phenotype and MRI findings in LBSL. To the best of our knowledge, such a dissociation has only previously been reported in two sisters diagnosed with asymptomatic LBSL due to compound heterozygous mutations in DARS2 [12]. On the other hand, the dissociation between clinical and radiological phenotypes has been reported in other forms of leukodystrophies [13, 14]. However, the biological basis of this dissociation has yet to be unraveled. In our opinion biochemical, radiological or genetic screening of healthy siblings of LBSL patients could be of value to rule out the presence of the disease. Detecting asymptomatic/minimally symptomatic patients is of value in premarital counseling, especially in countries where consanguineous marriage is common. Studies that are more comprehensive could determine the sensitivity, specificity and cost-effectiveness of such screening methods. Our study is the first to report cases of LBSL from sub-Saharan Africa. Nevertheless, functional studies are still needed to confirm the pathogenicity of the reported variants.

In conclusion, LBSL can show marked phenotypic variability even within the same family. This variable expressivity may complicate the detection of the causative variants in the context of genetic counseling.

\section{Abbreviations}

FLAIR: Fluid-attenuated inversion recovery; LBSL: Leukoencephalopathy, brainstem and spinal cord involvement and lactate elevation; MRI: Magnetic resonance imaging; OMIM: Online mendelian inheritance in man

\section{Funding}

This study was financially supported by the Agence Nationale pour la Recherche (to GS), the European Union (H2020, to GS) and the E-rare program (to GS). AY is a recipient of a Campus France and University of Khartoum fellowship. MAS was supported by the Deanship of Scientific Research, King Saud University, Riyadh, Saudi Arabia, via research group project number RGP-VPP-301. The funding bodies had no role in the design of the study, in the collection, analysis and interpretation of data or in writing the manuscript.

\section{Availability of data and materials}

Data (not including participants' personal information or identifiers) are available from the corresponding author upon reasonable request.

\section{Authors' contributions}

Study design and conception: GS, AEA, LE and AB2, acquisition of phenotypic and biological data: SME, MAS, AY, LE, SAE, AB1, RA, RI and SOMAT, bioinformatic analysis: AY, LE and MK, interpretation of MRIs: SOMAT, phenotypic-genotypic correlations and writing the first draft: $A Y, A B 1$ and $M A$, review and critique: SME, MAS, GS, AEA, AB2, MK, LE, RA, SAE, SOMAT and RI. All authors read and approved the final manuscript. All authors agreed to be accountable for all aspects of the work in ensuring that questions related to the accuracy or integrity of any part of the work are appropriately investigated and resolved.

\section{Ethics approval and consent to participate}

The study was approved by the Ethics committee of Paris-Necker Hospital (France) and the Ethics Committee of the University of Khartoum Medical Campus (Sudan). All participants agreed to participate in the study. Written informed consent was obtained from each patient and healthy family member before participation in the study. For participants under the age of 18 , written informed consents were obtained from their father.

\section{Consent for publication}

Signed informed consents were obtained from participants for publication of personal and medical details included in the case report. For participants under the age of 18 , signed consent for publication was obtained from their father.

\section{Competing interests}

The authors declare that they have no competing interests.

\section{Publisher's Note}

Springer Nature remains neutral with regard to jurisdictional claims in published maps and institutional affiliations.

\footnotetext{
Author details

${ }^{1}$ Department of Biochemistry, Faculty of Medicine, University of Khartoum, Khartoum, Sudan. ${ }^{2}$ Institute of Endemic Diseases, University of Khartoum, Khartoum, Sudan. ${ }^{3}$ Division of Pediatric Neurology, Department of Pediatrics, College of Medicine, King Saud University, Riyadh, Saudi Arabia. ${ }^{4}$ Department of Medicine, Faculty of Medicine, University of Khartoum, Khartoum, Sudan. ${ }^{5}$ Department of Neurology \& Epileptology, Hertie Institute for Clinical Brain Research, University of Tübingen, Tübingen, Germany. ${ }^{6}$ Department of Radiology, Dar Al Elaj specialized hospital, Khartoum, Sudan. ${ }^{7}$ Department of Physiology, Faculty of Medicine, University of Khartoum, Khartoum, Sudan. ${ }^{8}$ Department of Neurology, Soba University Hospital, Khartoum, Sudan. ${ }^{9}$ Department of Biochemistry, Faculty of Medicine, National University, Khartoum, Sudan. ${ }^{10}$ Ecole Pratique des Hautes Etudes, EPHE, PSL Research University, Paris, France. ${ }^{11}$ Department of Genetics, APHP, Pitié-Salpêtrière Hospital, Paris, France. ${ }^{12}$ Institut du Cerveau et de la Moelle épinière, INSERM U1127, CNRS UMR7225, Sorbonne Universités UMR_S1127, 75013 Paris, France. ${ }^{13}$ Department of Physiology, College of Medicine, King Saud University, Riyadh, Saudi Arabia.
} 
Received: 17 May 2018 Accepted: 17 October 2018

Published online: 23 October 2018

\section{References}

1. Van Der Knaap MS, Van Der Voorn P, Barkhof F, Van Coster R, KrägelohMann I, Feigenbaum A, et al. A new leukoencephalopathy with brainstem and spinal cord involvement and high lactate. Ann Neurol. 2003;53(2):252-8.

2. van Berge L, Hamilton EM, Linnankivi T, Uziel G, Steenweg ME, Isohanni P, et al. Leukoencephalopathy with brainstem and spinal cord involvement and lactate elevation: clinical and genetic characterization and target for therapy. Brain. 2014;137(Pt 4):1019-29.

3. Scheper GC, van der Klok T, van Andel RJ, van Berkel CGM, Sissler M, Smet J, et al. Mitochondrial aspartyl-tRNA synthetase deficiency causes leukoencephalopathy with brain stem and spinal cord involvement and lactate elevation. Nat Genet. 2007:39(4):534-9.

4. Aradjanski M, Dogan SA, Lotter S, Wang S, Hermans S, Wibom R, et al. DARS2 protects against neuroinflammation and apoptotic neuronal loss, but is dispensable for myelin producing cells. Hum Mol Genet. 2017 26(21):4181-9.

5. Sim N-L, Kumar P, Hu J, Henikoff S, Schneider G, Ng PC. SIFT web server: predicting effects of amino acid substitutions on proteins. Nucleic Acids Res. 2012:40(Web Server issue):W452-7.

6. Adzhubei I, Jordan DM, Sunyaev SR. Predicting functional effect of human missense mutations using PolyPhen-2. Curr Protoc Hum Genet 2013 Jan; Chapter 7:Unit7.20

7. Schwarz JM, Cooper DN, Schuelke M, Seelow D. MutationTaster2: mutation prediction for the deep-sequencing age. Nat Methods. 2014;11(4):361-2.

8. Landrum MJ, Lee JM, Riley GR, Jang W, Rubinstein WS, Church DM, et al. ClinVar: public archive of relationships among sequence variation and human phenotype. Nucleic Acids Res. 2014;42(Database issue):D980-5.

9. Karczewski KJ, Weisburd B, Thomas B, Solomonson M, Ruderfer DM, Kavanagh D, et al. The ExAC browser: displaying reference data information from over 60000 exomes. Nucleic Acids Res. 2017:45(D1):D840-5.

10. Finsterer J, Zarrouk-Mahjoub S. Phenotypic spectrum of DARS2 mutations. J Neurol Sci. 2017;376:117-8.

11. van Berge L, Kevenaar J, Polder E, Gaudry A, Florentz C, Sissler M, et al. Pathogenic mutations causing LBSL affect mitochondrial aspartyl-tRNA synthetase in diverse ways. Biochem J. 2013;450(2):345-50.

12. Labauge P, Dorboz I, Eymard-Pierre E, Dereeper O, Boespflug-Tanguy O. Clinically asymptomatic adult patient with extensive LBSL MRI pattern and DARS2 mutations. J Neurol. 2011;258(2):335-7.

13. Di Bella D, Pareyson D, Savoiardo M, Farina L, Ciano C, Caldarazzo S, et al. Subclinical leukodystrophy and infertility in a man with a novel homozygous CLCN2 mutation. Neurology. 2014;83(13):1217-8.

14. Abrams CK, Scherer SS, Flores-Obando R, Freidin MM, Wong S, Lamantea E, et al. A new mutation in GJC2 associated with subclinical leukodystrophy. J Neurol. 2014;261(10):1929-38.

Ready to submit your research? Choose BMC and benefit from:

- fast, convenient online submission

- thorough peer review by experienced researchers in your field

- rapid publication on acceptance

- support for research data, including large and complex data types

- gold Open Access which fosters wider collaboration and increased citations

- maximum visibility for your research: over $100 \mathrm{M}$ website views per year

At $\mathrm{BMC}$, research is always in progress.

Learn more biomedcentral.com/submissions 